\section{Crystalloids in salivary gland lesion: A diagnostic clue}

Sir,

Fine-needle aspiration (FNA) of the cystic lesion of the head and neck region usually yields fluidy aspirate and is usually given a nonspecific diagnosis on cytomorphological examination. However, at times, some acellular structures may provide a diagnostic clue toward a benign or malignant etiology. ${ }^{[1-3]}$ Crystalloids may be seen in a variety of salivary gland lesions. Their presence is not common, but sometimes can be seen in benign as well as malignant lesions. ${ }^{[2-5]}$ Among various crystals found in the gland, amylase crystals have been reported only in benign lesions of the gland, as noted in our case.

A 67-year-old male presented to the hospital with swelling at the angle of mandible region on the left side for the last 3-4 days. The swelling was painful. The patient was known hypertensive and diabetic and was on medication for the same. However, there was no history of fever, weight loss, dysphagia, or odynophagia. On examination, the swelling was located below the left ear lobule, was mildly tender, diffuse with regular margins, and measured approximately $2.5 \mathrm{~cm} \times 2.5 \mathrm{~cm}$ [Figure 1a]. No other swelling or any other lymph node was noted. Systemic examination also did not reveal any abnormality. The patient was started on antibiotics and ultrasound was advised for the swelling.

Ultrasound of the left parotid region showed a $29 \mathrm{~mm} \times 21 \mathrm{~mm} \times 20 \mathrm{~mm}$ nodal mass in the

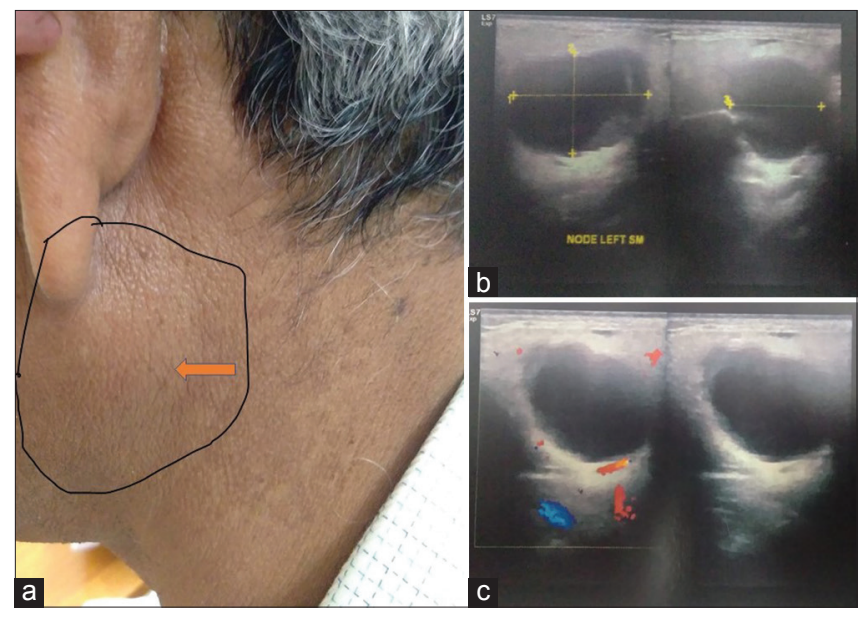

Figure 1: (a) A diffuse swelling noted below left ear lobule measuring approximately $2.5 \mathrm{~cm} \times 2.5 \mathrm{~cm}$, (b and c) ultrasound of left parotid region showing a $29 \mathrm{~mm} \times 21 \mathrm{~mm} \times 20 \mathrm{~mm}$ nodal mass in the left parotid gland with cystic degeneration and necrosis left parotid gland with cystic degeneration and necrosis [Figure $1 \mathrm{~b}$ and $\mathrm{c}$ ]. Ultrasound-guided FNA was done and yielded mucoid material. Smears prepared showed predominantly acute and chronic inflammatory cells mixed with numerous crystalloids which were rectangular to rhomboid in shape with long parallel sides; some with pointed ends [Figure 2a-c]. They stained deep blue on Giemsa [Figure 2a and b], suggestive of amylase crystals. No ductal or acinar cells were found. Cytological features along with clinicoradiological findings were suggestive of benign etiology with possibility of obstruction and inflammation.

The different types of crystalline structures noted can be amylase, tyrosine, collagenous, oxalate, and intraluminal crystalloids. It is important to recognize the type of crystalloid as they may be helpful in differentiating the neoplastic as well as nonneoplastic lesions. ${ }^{[2-5]}$ In 1993, Jayaram et al. were the first to describe such crystalline structures in FNA of benign cystic parotid glands. ${ }^{[2]}$ It is important to identify and differentiate other types of crystalloids from amylase crystals because these crystals can be seen in malignant salivary gland tumors whereas amylase crystalloids are found in only benign lesions including chronic sialadenitis, unilocular cysts, and lymphoepithelial cysts. ${ }^{[3-5]}$

Amylase crystalloids are nonbirefringent geometric, polygonal, rhomboid-shaped structures with pointed ends and were first observed by Takeda and Ishikawa in a human salivary duct cyst in 1983. ${ }^{[3]}$ Tyrosine-rich crystalloids have sun-burst or petal-shaped morphology with blunt ends, seen in pleomorphic adenomas and rarely in malignant salivary gland neoplasms. Collagenous crystalloids are seen as radially arranged needle-shaped fibers of collagen. They are found in pleomorphic adenomas and myoepitheliomas. Intraluminal crystalloids

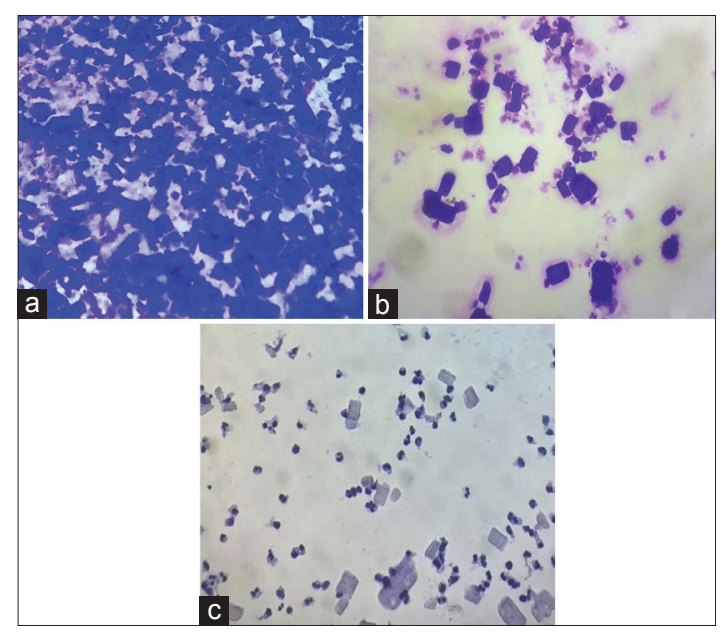

Figure 2: (a-c) Smears showing mainly acute and chronic inflammatory cells mixed with numerous crystalloids which were rectangular to rhomboid in shape with long parallel sides, some with pointed ends, suggestive of amylase crystals 
composed of dense amorphous eosinophilic material are described in malignant salivary gland tumors.

It is a well-known fact that cystic degeneration can be noted in cases of malignant lesions such as squamous cell carcinoma; hence, before rendering a benign diagnosis in the presence of amylase crystals, multiple aspirations and histological examination from the salivary gland lesions should be done. A diagnosis of sialadenitis should be kept in mind while evaluating aspirates from the salivary gland lesions. The presence of type of crystalloids must be reported on cytology and/or histology as it will point toward the nature of the lesion. Hence, making a correct diagnosis will help clinicians in avoiding unnecessary surgical intervention in such cases.

\section{Declaration of patient consent}

The authors certify that they have obtained all appropriate patient consent forms. In the form the patient(s) has / have given his/her/their consent for his/her/their images and other clinical information to be reported in the journal. The patients understand that their names and initials will not be published and due efforts will be made to conceal their identity, but anonymity cannot be guaranteed.

\section{Financial support and sponsorship}

Nil.

\section{Conflicts of interest}

There are no conflicts of interest.

Manjari Kishore, Manju Kaushal, Shruti Dogra Department of Pathology, Post Graduate Institute of Medical Education and Research, Dr. Ram Manohar Lohia Hospital, New Delhi, India E-mail:drmanjarik@gmail.com

\section{References}

1. Paker I, Anlar M, Genel N, Alper M. Amylase crystalloids on fine-needle aspiration of salivary gland. Turk J Pathol 2010;26:153-5.

2. Jayaram G, Khurana N, Basu S. Crystalloids in a cystic lesion of parotid salivary gland: Diagnosis by fine-needle aspiration. Diagn Cytopathol 1993;9:70-1.

3. Takeda Y, Ishikawa G. Crystalloids in salivary duct cysts of the human parotid gland. Scanning electron microscopical study with electron probe X-ray microanalysis. Virchows Arch A Pathol Anat Histopathol 1983;399:41-8.

4. Boutonnat J, Ducros V, Pinel C, Kieffer S, Favier A, Garin J, et al. Identification of amylase crystalloids in cystic lesions of the parotid gland. Acta Cytol 2000;44:51-6.

5. Gerhard R, Vargas PA, da Cruz Perez DE, Fregnani ER. Fine-needle aspiration biopsy of parotid cystic lesion with crystalloid formation. Diagn Cytopathol 2005;32:378-9.

This is an open access journal, and articles are distributed under the terms of the Creative Commons Attribution-NonCommercial-ShareAlike 4.0 License, which allows others to remix, tweak, and build upon the work non-commercially, as long as appropriate credit is given and the new creations are licensed under the identical terms.

\begin{tabular}{|l|l|}
\hline \multicolumn{2}{|c|}{ Access this article online } \\
\hline Quick Response Code: & \\
\hline & Website: \\
\hline & www.jlponline.org \\
\cline { 2 - 2 } & \\
\hline
\end{tabular}

How to cite this article: Kishore M, Kaushal M, Dogra S. Crystalloids in salivary gland lesion: A diagnostic clue. J Lab Physicians 2019;11:100-1.

@ 2019 Journal of Laboratory Physicians | Published by Wolters Kluwer - Medknow 